\title{
COMUNIDADES TERRITORIALES Y MARGINALIDAD: GALICIA EN LAS RELACIONES DE CAUSAS PENDIENTES $(\mathbf{1 7 8 7})^{*}$
}

\author{
Antonio RISCO \\ Universidad de Toulouse-Le Mirail
}

\begin{abstract}
Resumen
Más allá de su articulación con la ilustrada -y poco desarrollada- reforma penal del siglo XVIII, el expediente de las «causas pendientes», abierto a raíz de la R.O. de 23 de mayo de 1783 (Lardizábal acababa de publicar su Discurso sobre las penas), constituye un precioso indicador -no por puntual menos preciso- de la criminalidad y la violencia en la España de las Luces. Tiene, además, -y éste será el aspecto esencialmente atendido en este artículo- un interés intrínseco en orden al conocimiento de las relaciones entre «centro» y «periferia» (geográfica, institucional, social...) y al de la realidad de una significativa porción del territorio español: en el supuesto, el territorio gallego.
\end{abstract}

\begin{abstract}
Beyond its link with the enlightened but little developped reform of the penal system in the eighteenth century, the case of causes to appear in Court, which was set by Royal Will on Mayo 23rd 1783 (Lardizábal had just published his Essay on Punishment) gives interesting information on violence and criminality in enlighted Spain. Moreover, and this is what will be developped in this article, the reader will find a true interest in the link between the «centre» and the «perighry» (geographically, institutionally, socially..) This artical also deals with a study of a quite exciting part of the Spanish territory (Galicia)
\end{abstract}

En un trabajo anterior ${ }^{1}$ tuve ocasión de estudiar el trasfondo y el verdadero sentido de un aspecto importante de la inconclusa reforma penal ilustrada, el que puso en marcha, precisamente, la Real Orden de 23 de mayo de 1783 al ordenar la confección de unas relaciones de causas pendientes destinadas a proporcionar a S.M. Carlos III una

* Contiene este trabajo la elaboración de los materiales utilizados en un seminario de doctorado impartido, en abril de 2000, en el Departamento de Historia Medieval y Moderna de la Universidad de Alicante.

1. A. Risco, «Las relaciones de causas pendientes. Un aspecto inédito del reformismo ilustrado», en Actas del Congreso Internacional El Conde de Aranda y su tiempo (Zaragoza, 1-5 de diciembre de 1998). 
«noticia» del estado de la administración de justicia y de la criminalidad en sus reinos ${ }^{2}$. Hoy me propongo indagar la aplicación de aquellas medidas, dado el interés intrínseco que ofrecen dichas relaciones en orden al conocimiento de las correlaciones entre centro y periferia (geográfica, institucional, social...) en la sociedad española del siglo XVIII.

Las relaciones de causas pendientes constituyen un precioso indicador de la litigiosidad, la criminalidad y la violencia en la España de las Luces. En términos cuantitativos, las causas pendientes no prejuzgan del volumen de causas instruidas en los diferentes tribunales españoles, pero, en la medida en que no hay razón a priori para imaginar que los jueces de Aragón, por ejemplo, eran más perezosos que los de Sevilla o Mallorca, la cuantificación de los datos y su comparación suministran un baremo de criminalidad, totalmente operativo si pensamos que a mayor número de causas pendientes puede también corresponder una mayor gravedad o intensidad en el delinquir. Así, si comparamos las cifras relativas al mes de julio de 1787, la clasificación que se obtiene, por audiencias, es la siguiente:

\section{CAUSAS PENDIENTES}

$\begin{array}{lr}\text { GALICIA } & 141 \\ \text { ARAGÓN } & 28 \\ \text { VALENCIA } & 21 \\ \text { SEVILLA } & 13 \\ \text { CANARIAS } & 12 \\ \text { CATALUÑA } & 11 \\ \text { MALLORCA } & 10 \\ \text { ASTURIAS } & 3 \\ \text { NAVARRA } & 3\end{array}$

\section{CAUSAS SENTENCIADAS}

$\begin{array}{lr}\text { GALICIA } & 27 \\ \text { ARAGÓN } & 47 \\ \text { VALENCIA } & 36 \\ \text { CATALUÑA } & 16 \\ \text { SEVILLA } & 9 \\ \text { CANARIAS } & 1 \\ \text { MALLORCA } & 1 \\ \text { ASTURIAS } & 1\end{array}$

GALICIA

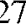

47

36

16
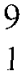

Adviértase la coincidencia, en cabeza de la clasificación, de los territorios correspondientes a las audiencias de Aragón ${ }^{3}$ y de Valencia. ¿Cabe hablar, por ello, de una mayor criminalidad en los antiguos territorios de la Corona de Aragón? Quizás no, pero si de una mayor criminalización, por la inclusión de los vagos en esas relaciones, indicio probable del mayor número de vagos existente en esas zonas -que son también, huelga recordarlo, las más pobladas-, pero, sobre todo, certificación del mayor celo puesto por los agentes del control social en el recogimiento de los vagos. La

2. A.H.N., Estado, 3156-2. En este voluminoso expediente sobre «la comisión de causas pendientes que tuvo a su cargo Don Benito de la Peña», se refieren las medidas adoptadas por S.M. para acelerar el funcionamiento de la administración de justicia, y el método impuesto a los Tribunales para la confección de las relaciones mensuales de causas pendientes. Utilizando una fuente distinta, pero de similar naturaleza, J. M. Palop Ramos ha estudiado los «Delitos y penas en la España del siglo XVIII», in Estudis, 22, 1996, p. 65-103.

3. Las cifras correspondientes a las causas sentenciadas en la audiencia de Aragón son una media mensual establecida a partir del dato que recogen los documentos (189 causas sentenciadas en los cuatro meses anteriores a julio de 1787). 
razón no es difícil de descubrir. La audiencia de Aragón se refiere, explícitamente, a «los muchos vagos que resultan aplicados», es decir condenados a trabajar en las obras del canal de Aragón. En los cuatro meses anteriores a julio de 1787 habían sido sentenciados 189 reos «a las armas y canal».

A las armas -concretamente a los arsenales militares de Cartagena- serían, probablemente, «aplicados» también los vagos valencianos, pues la relación de Valencia menciona las 36 causas determinadas "con inclusión de los vagos». Las demás audiencias «nada dicen» sobre la cuestión, cosa que se les reprocha, de modo que parece que fuesen menos diligentes en esta materia. ¿Por qué razones? Posiblemente por lo engorroso que resultaba recoger a los vagos cuando no había «destino» inmediato que darles o cuando la exclusión alcanzaba mayor intensidad. Es lo que ocurre, por ejemplo, en Navarra, en donde se advierte que «para los vagos y mujeres faltaba destino, por no admitir aquéllos en el Hospicio la ciudad, a cuyo cargo corre, y menos a éstas», lo que, fatalmente, llevaba a acentuar la criminalización de los comportamientos y sus consecuencias, como advertía el Consejo Real de Navarra al señalar, haciendo gala de humanidad, que las mujeres rechazadas en el Hospicio eran enviadas a la cárcel, «resultando de ponerlas en la cárcel mayor su abandono».

También resultaba, posiblemente, engorroso (y oneroso) organizar expediciones de vagos al punto de destino asignado para su «aplicación». Por ello, en los territorios en que este destino quedaba más próximo (Aragón, con el canal, o el país valenciano, con los arsenales), cuando había necesidad de mano de obra, las audiencias se mostraban más activas y diligentes, acelerando la determinación de las causas pendientes, tal como querían las ilustradas autoridades supremas, para hacer sitio a los vagos, tanto en las sentencias como en las cárceles o recogimientos por donde transitaban.

La comparación de lo que ocurría en las dos chancillerías de Valladolid y Granada es asimismo interesante. En primer lugar, se observa una importante diferencia cuantitativa. En junio de 1787, hay 81 causas pendientes en Granada y tan sólo 17 en Valladolid, en donde los acusados detenidos son menos de cuarenta. Ese mismo mes, se habían juzgado 149 causas en Granada, y no más de 29 en Valladolid. El elevado número de causas tratadas en Granada puede explicarse, en parte, por el celo desplegado en materia de vagos - la Chancillería hace saber que se proseguían eficazmente la detención y asignación de destino de los vagabundos-, probablemente en razón de la política de «limpieza» seguida para la puesta en práctica del proyecto de colonización de Sierra Morena. Pero este hecho no explica todo.

Las cifras son elocuentes. Mientras que en Valladolid, son examinadas y juzgadas hasta 500 causas, en Granada, tan sólo en el año 1788, se juzgan 971 causas más que en 1787; casi el doble que en Valladolid. Por eficaz que fuese el arresto de vagabundos en la demarcación de Granada, ello no basta para explicar la diferencia. La eventualidad de una mayor rapidez granadina en la expedición de los asuntos conforme quería el gobierno, tampoco parece explicación suficiente. Cabe deducir, pues, y ahora en términos de criminalidad y no de simple criminalización, que, al sur del Ta- 
jo, había más delincuentes que al Norte, diferencia que tampoco queda satisfactoriamente explicada por la simple consideración de la distinta densidad demográfica.

Hay que preguntarse, entonces, si había más delincuencia o si lo que había era otra delincuencia. La comparación entre ambas Chancillerías resulta reveladora, pero conviene completar el panorama que contemplamos al Norte y al Sur del Tajo, atendiendo a lo que ocurría en dos grandes ciudades como Madrid y Sevilla, y observando el contrapunto suministrado por un territorio eminentemente rural, cual era Galicia. Ello con las lógicas y prudentes reservas que impone la correlación de territorios espacial, demográfica y aún socialmente dispares.

Al Norte del Tajo - Chancillería de Valladolid- la sociedad que los procesos nos revelan, no es una sociedad violenta, o bien la violencia es sobre todo de carácter ver$\mathrm{bal}^{4}$. Las injurias, las «palabras» pronunciadas contra la honorabilidad de un tercero constituyen el motivo de denuncia o de inculpación que más frecuentemente llega hasta los magistrados de la Chancillería de Valladolid, y supone el $30,37 \%$ del total en 1789. El insulto -las palabras- es, pues, percibido como algo realmente insoportable en la comunidad, generalmente rural, en que éste se produce ${ }^{5 .}$ Por otra parte, en la criminalidad registrada hay más hechos violentos (homicidios y heridas: $18,86 \%$ ) que robos (hurtos y latrocinios: 13,20\%); si consideramos, sin embargo, la forma más grave de la violencia física, es decir los homicidios $(3,77 \%)$, en relación con los robos, vemos que éstos priman ampliamente sobre aquéllos. Podría, pues, adelantarse la idea de que, al Norte del Tajo, la sociedad española es una sociedad con rasgos arcaizantes -peso de las injurias en la litigiosidad-en la cual no se ha realizado aún el paso de una criminalidad de violencia a una criminalidad de atentados al bien ajeno -hay más de la primera que de la segunda-, aunque se perciben claramente los rasgos de esta evolución -hay más hurtos que homicidios-.

Veamos ahora lo que ocurría al Sur del Tajo y, concretamente, en Sevilla. Los informes procedentes de la Audiencia de Sevilla ${ }^{6}$ muestran una sociedad en la que el porcentaje de atentados a las personas $(41,30 \%)$ es también superior al de los atentados a los bienes $(32,60 \%)$, y en proporciones sensiblemente superiores a las registradas en la Chancillería de Valladolid. Se trata, pues, de una sociedad más violenta, en la que la agresión verbal no parece presentar el mismo carácter compensatorio o sustitutivo que en los territorios situados al Norte del Tajo.

En una sociedad aparentemente menos permeable a los modelos nobiliarios, al menos en sus capas populares, la venganza privada, actualizada mediante fórmulas inmediatas -altercado, ajuste de cuentas más o menos pérfido y a veces desplazado hacia miserables bienes o hacia la herramienta de trabajo-, conserva cierto valor co-

4. A. Risco, «Violence réelle, violence légale en Castille au XVIIIe siècle», en La justice criminelle devant l'Europe des Lumières, Université de Toulouse-Le Mirail, 1982, p. 74-98.

5. Revelan estos datos un universo mental y social que bien puede relacionarse con el que $\mathrm{Y}$. Castan ha puesto de manifiesto al estudiar el mediodía francés (Y. Castan, Honnêteté et relations sociales en Languedoc.1715-1780, Paris, 1974).

6. Las relaciones estudiadas cubren los meses de abril, mayo y junio de 1788 . 
munitario y traduce la repugnancia ancestral a poner entre las manos del juez -el Estado- la competencia de la reparación, es decir la violencia legal. En términos generales, y sin minusvalorar la importancia zonal del bandolerismo, dado que el porcentaje de robos es también superior al encontrado en la Chancillería de Valladolid, podría afirmarse que la sociedad andaluza parece ser una sociedad más criminógena, en la que la Justicia impone difícilmente una presencia excluyente de las iniciativas privadas.

En una carta dirigida a Floridablanca el 19 de abril de 1788, Campomanes le informa de que la Chancillería de Granada le ha advertido de que resulta casi imposible precisar el estado de las causas criminales graves y de menor gravedad, así como las que corren entre partes, pues son a menudo abandonadas por los fallecimientos o los entendimientos que se producen. Estos entendimientos a que aluden los magistrados de Granada actualizan el perdón de la parte ofendida, reconocido por la antigua legislación y concretado en el pago de una suma u otro arreglo entre partes, que legisladores y jueces interpretaban de manera restrictiva, tratando de restringir una práctica que, por lo que se ve, no era inusual al Sur del Tajo. Como la venganza privada, esta práctica anulaba o limitaba la presencia del Estado al introducir un margen de disponibilidad personal en una materia en la que el Estado, en el último tercio del siglo XVIII, no se contenta con tener la última palabra, sino que quiere ser el único en tener la voz y el voto.

A la luz de esta realidad andaluza, insensible o refractaria a la presencia del aparato judicial, debe ser interpretado, a mi juicio, el mayor voluntarismo mostrado por este último a la hora de concretar la intrusión en el ámbito privado propiciada por el celo reglamentista del siglo. Encontramos buena prueba de ello en la represión de los delitos sexuales, relativamente intensa en la demarcación de la Audiencia de Sevilla $(10,86 \%)$, lo cual no es incompatible con una lectura que nos haría ver la imagen de una sociedad de costumbres más libres, $\mathrm{o}$, al menos, más exteriorizadas, $\mathrm{y}$, por ende, más fácilmente reprimibles.

Sevilla era una gran ciudad; comparémosla con Madrid para darnos cuenta de una diferencia fundamental. En Madrid se ha operado ya el paso de una criminalidad de violencia a una criminalidad de latrocinio, índice de una innegable transformación social y mental. Desde septiembre de 1787 hasta febrero de 1788 , más de la mitad de los delitos perseguidos por la Sala de Alcaldes de Casa y Corte -precisamente el $55 \%$ - entran dentro de la segunda categoría. Hay, pues, menos criminalidad de violencia (35\%) que de latrocinio, e incluso en la rúbrica de delitos diversos $(10 \%)$ nos encontramos con un $7,5 \%$ de comportamientos delictivos de carácter económico (ocultación de fondos, falsificación, estafa). Una nota dirigida a Campomanes el 24 de septiembre de 1788 le advierte de que en el informe de las causas pendientes en los tribunales de Madrid no se registran muchos delitos graves, aludiéndose, en particular, a los hurtos. Ello indica, por una parte, que tales infracciones eran consideradas severamente -son incluidas entre los delitos graves-, aunque, por otra parte, dada su insuficiente represión -pocas de estas infracciones aparecen consignadas en los regis- 
tros-, los tenientes de corregidor de Madrid y los agentes que operaban bajo su jurisdicción habían banalizado, hasta cierto punto, tales comportamientos delictivos.

Siempre cabe la duda, naturalmente, de que los informes remitidos a la autoridad superior fueran reflejo fidedigno de lo que ocurría en los tribunales del Reino. Razonablemente, la firmeza e insistencia del gobierno, así como, en una fase ulterior, la amenaza de una «inspección» superior, pueden llevarnos a pensar que los informes no disfrazaron demasiado la realidad. De lo que no cabe duda, en cambio, es de que los agentes del aparato no habían asumido totalmente el ideal de humanización proclamado por los gobernantes al abrir el expediente de las causas pendientes. Cuando la Sala de Alcaldes adopta ciertas medidas para que nadie ingrese en prisión sin que lo sepa la Sala, el covachuelista Díaz de la Peña, encargado del seguimiento del expediente, anota el abuso que inmediatamente se produce. Los escribanos -anota Díaz de la Peña con sincera indignación- no los envían a la cárcel, sino que los retienen en los barrios.

Quizás sea ésta la ilustración de una interpretación, actualizada al gusto de la capital, si no del perdón de la parte ofendida, al menos del de la justicia reparadora. La Justicia, en sus escalones subalternos o inferiores, y en razón de inconfesables transacciones, podía mostrarse interesada y, en ocasiones, complaciente. También sé, añadía Díaz de la Peña, que hay muchas más causas que las que figuran en el informe, pero son interrumpidas durante su instrucción, en particular cuando se trata de raterías «gordas». Advirtamos como el otrora rígido covachuelista, influenciado quizás por el laxismo imperante en la materia, adapta -iinconscientemente?- su lenguaje, al calificar las mencionadas raterías no de «graves» sino de «gordas». Utiliza, pues, un registro popular y coloquial, inhabitual en la prosa con la que se trata de los asuntos delictivos. Decididamente, en Madrid, a finales de siglo, la delincuencia económica estaba como pez en el agua, y esta realidad formaba parte de la cotidianeidad de los habitantes de la villa y Corte.

Con todo, la audiencia que más causas instruía y la que más causas pendientes tenía $^{7}$ era la Audiencia de Galicia. Las cifras son elocuentes: 141 . Aunque la primera parte de la relación gallega se refiriese sobre todo a los robos ${ }^{8}$, hay que fijarse en que la criminalidad era más bien, en este territorio, una criminalidad de violencia $(36,3 \%$ si contabilizamos conjuntamente muertes y malos tratos) que de robo $(25,05 \%)$, y en que el porcentaje de muertes violentas $(24,4 \%)$ era casi similar al de robos.

7. Esta observación es reiterada en las notas de Benito Díaz de la Peña. La sorpresa que manifiesta al referirse a la Audiencia de Galicia, en su correspondencia con las autoridades superiores, se tiñe de indignación: en dicha Audiencia, más que en ninguna otra del Reino, se procede con mucha lentitud y negligencia, tanto en lo referente a la instrucción de las causas como a la custodia de los acusados (11-X1787); la práctica seguida en la instrucción procesal se opone, en Galicia, a la de los demás tribunales de S.M. (9-II-1788).

8. La Relación de causas pendientes de la Audiencia de Galicia correspondiente al mes de junio de 1787 incluye 168 delitos, por este orden: robos 43 ; muertes violentas 41 ; amancebamientos 37 ; malos tratos 20 ; otros tratos ofensivos 27 . 
La impotencia del Estado es, a veces, flagrante: en la noche del 5 de octubre de 1762, Don Manuel Bermúdez de Castro, cura de Paradela, es víctima de una agresión. El agredido denuncia un robo acompañado de malos tratos. A resultas de la denuncia es detenido Francisco Antonio Clemente, escribano; otras personas fueron también acusadas y una desgraciada (sic) mujer, presuntamente implicada en el robo, fue incluso sometida a tortura. Pues bien, veinticinco años más tarde, la causa seguía pendiente. En 1786, el fiscal de S.M. decide proseguir la instrucción, lo que, de no haber fallecido antes, quizás hubiese permitido al cura de Paradela obtener reparación. No sabemos si las otras personas concernidas tuvieron tan triste fin: ningún agente judicial fue capaz de atestiguar si durante todo ese tiempo los acusados habían permanecido en la cárcel, lo que parece, desde luego, poco probable.

Aunque tales hechos, vistos desde Madrid, constituyeran un «abuso intolerable», no era el único imputable, en Galicia, a la administración de justicia. Obviamente, desde la perspectiva reivindicadora de méritos y competencias propia de los letrados ilustrados, no era difícil resaltar las prácticas y comportamientos vigentes en los escalones inferiores del aparato. Pero cuando la denuncia alcanzaba a los magistrados de la Audiencia de La Coruña, y en aspectos relevantes de su tarea, cabe entender la preocupación de las autoridades centrales.

El 14 de agosto de 1792, el abogado Francisco Somoza se dirige directamente al Rey, haciéndole partícipe de la causa de «un desgraciado labrador», que había sido ejecutado, a pesar de la apelación interpuesta contra la sentencia pronunciada por la Sala del Crimen de La Coruña. La ley permitía a cualquier acusado condenado a la pena capital la presentación de un recurso ante la Chancillería de Valladolid, pero, Somoza dixit, el tribunal gallego había adoptado la perniciosa práctica de hacer sus sentencias ejecutorias sin esperar el resultado de la apelación. El abogado veía en esta práctica una violación intolerable de los derechos humanos, pues así «la vida de muchos (y quizás, a veces, la de inocentes) dependía de una sola sentencia». Además, aquellos desgraciados se veían privados del derecho, tan natural y tan prestamente garantizado por el soberano, a un nuevo examen de su conducta, a un nivel superior, en un proceso en el que estaban en juego sus vidas.

Constituye esta argumentación un muestrario ejemplar de las categorías mentales del letrado ilustrado. Desconfianza en relación con el sistema vigente (la eventual condena de inocentes), aprensión ante las decisiones soberanas incontrolables (una sola sentencia), filantropía reformista (la reiterada utilización del término «desgraciados»), y, al tiempo, exigencia de un derecho «natural» y de la garantía que supone su instrumentación legal -o codificación - por la instancia suprema. Aunque la formulación (la protección del soberano) conserve relentes del pasado, la intención reivindica, con claridad, una puesta al día.

Con todo, lo más grave no es el caso referido por el abogado Somoza, sino la afirmación de que la Audiencia de Galicia, al actuar de tal guisa con el pobre labrador defendido por Somoza, no hacía sino seguir «la práctica casi común a todos los tribunales del Reino». Naturalmente, sólo un estudio circunstanciado y basado en las co- 
rrelativas series, permitiría ponderar el alcance de tal afirmación. Hay un hecho, sin embargo, que tiende a relativizar la plausible exageración del abogado, y es que su denuncia, tal como pedía, fue transmitida al Consejo de Castilla, lo que prueba que el mensaje había sido atendido. La consulta al Consejo era necesaria, en efecto, antes de promulgar una ley general estableciendo la obligación, en ciertos casos, de la apelación ante los tribunales superiores. Adviértase, por último, que la denuncia de Somoza era menos el resultado de un vacío legislativo que el del olvido, voluntario o negligente, de la legislación existente por parte de unos tribunales arrogantes, que, al finalizar el siglo, se han endurecido.

Otro punto debe ser tenido en cuenta: la inexistencia de vagos en Galicia, al menos en términos administrativos. «Nada se dice de la recolección de vagos», observa el covachuelista Díaz de la Peña al anotar la relación de la Audiencia gallega correspondiente al mes de junio de 1787. ¿Quiere decir ello que, en Galicia, no había vagos? En Galicia, nos dice R.M. Pérez Estévez, el número de vagos recogidos no es desdeñable, aunque no es muy elevado si se relaciona con la numerosa población del territorio gallego". ¿A qué razones podía obedecer, pues, esta aparente indiferencia de las autoridades locales ante un tema de alcance nacional?

Más valdría, quizás, hablar de ineficacia que de indiferencia, o, en cualquier caso, ésta no es sino la consecuencia de aquélla. Campomanes refiere, en carta a Floridablanca, hasta que punto son «infructuosas» todas las «diligencias» realizadas en Galicia en materia de vagos.

La explicación hay que buscarla tanto en ciertos elementos generales -los reunidos por R.M. Pérez Estévez-, como en otros más específicos de la realidad gallega. Obviamente, la mayor o menor eficacia de la «recolección» de vagabundos dependía del mayor o menor celo desplegado: cuando no iban más allá del proyecto, las obras de envergadura o la utilización paramilitar de los vagabundos, que en otros territorios de la Corona (Aragón, Levante...) incitaban a su persecución, no representaban estímulo alguno para las autoridades. Podríamos hablar, pues, de una falta de interés administrativo por la «recolección», lo que también explicaría que, en Galicia, preocupase menos la fijación coyuntural del concepto de «vago», en función del perfil tan insatisfactoriamente dibujado por el legislador y en relación con otras categorías conexas, como los mendigos, los malentretenidos, las mujeres abandonadas, etc.

Hay también una explicación local del fenómeno: la asimilación de tan indefinido grupo a otros -más que criminógenos, criminales- parecía evidente en tierras gallegas, en las cuales, se nos dice, «la mayor parte de los de esta especie» se dedica a robar. Ello nos descubre a un vago gallego menos ocioso que activo en el delinquir, quizás porque, en Galicia, los vagabundos como los labradores pasaban más hambre que en otras zonas de la Península. Unas zonas a las que llegaban los gallegos buscando medios de subsistencia, o huyendo de la Justicia o la «recolección». Así que

9. R. M. Pérez Estévez, El problema de los vagos en la España del siglo XVIII, Madrid, 1976, p. 119,123124. 
esta emigración/huida, que llevaba a algunos a Portugal y a muchos a Castilla (sic), bien podría explicar la ineficacia gallega en la recogida de vagos. No es que no hubiese vagos en Galicia, es que muchos de ellos partían buscando climas más clementes.

Pero los vagabundos no eran los únicos que se iban de Galicia. En su respuesta a las amonestaciones madrileñas, la indócil Audiencia gallega insiste en la «ausencia» frecuente de los acusados y en la «atrocidad» de los delitos cometidos en su jurisdicción. El 19 de abril de 1788, Campomanes daba cuenta a Floridablanca de la manera en que la Audiencia de La Coruña explicaba el elevado número de causas pendientes diciendo que algunas eran incluidas en las relaciones porque habiendo sido juzgadas quizás (sic) por contumacia, los escribanos las habían dado por pendientes. Así, según los magistrados coruñeses, sólo tenían retraso ocho causas «bastante atroces» que estaban instruyéndose, probablemente con la lentitud inherente al desvelamiento de tales atrocidades. Con todo, en una correspondencia ulterior (27-VI-1788), Campomanes advertía que la última relación remitida por la Audiencia gallega había sido dispuesta en los mismos términos y con la confusión habitual, sin que el modelo propuesto por Madrid hubiese sido tenido en cuenta. En descarga de los indisciplinados magistrados coruñeses observaba, sin embargo, que habían acelerado y juzgado las causas que estaban pendientes desde hacía muchos años, por lo que no había ya retraso considerable. La relación de julio de 1788 fue entregada, además, según el «nuevo método» o modelo propuesto por el poder central, aunque no parece que estas buenas disposiciones durasen mucho tiempo.

Cinco años más tarde, cuando el expediente de las causas pendientes llega a manos del Conde de la Cañada, el balance de la situación gallega ofrece más elementos de permanencia que de cambio. Así, se dice, sigue habiendo numerosas causas detenidas, a causa de la incuria de los denunciantes o de la ignorancia de los jueces, porque, en este Reino, casi todos son pedáneos o legos, ya que, en muchos lugares, son nombrados por los señores. Y si los procesos se eternizan es porque, al no haber suficientes prisiones para custodiar a los acusados, los procesos en rebeldía instruidos contra los muchos acusados que huyen a Portugal, permanecen en manos de los escribanos ${ }^{10}$.

Vemos, pues, que, en el caso gallego, parece haber ciertos elementos estructurantes, que, más allá de la indisciplina denunciada y de sus posibles correcciones, pueden explicar la situación, a condición de no quedarse en la imagen negativa que, con razón o sin ella, se perfila desde las instancias centrales y de prestar atención al discurso exculpatorio de los magistrados coruñeses. En una carta dirigida a Floridablanca (4-V-1787), el Regente de la Audiencia de La Coruña, deseoso de proteger a los magistrados a sus órdenes y de protegerse al mismo tiempo, anunciaba el envío de motivos y razones, pues no era justo, decía, que dichos jueces fuesen, en algún modo, descalificados en el bondadoso corazón del Rey, siendo así que todos los días obser-

10. Informe del Conde de la Cañada fechado el 24 de diciembre de 1793. 
vaba lo mucho que trabajaban. Naturalmente, nos interesa menos el «espíritu de trabajo» de los magistrados coruñeses que los motivos y los argumentos aducidos por el Regente.

Giran éstos en torno a la idea de que Galicia era un territorio al que había que referirse como un verdadero caso aparte dentro del mosaico español ". Como sabemos, en junio de 1787, la Audiencia de La Coruña ostentaba el record de causas pendientes (141), lo que la situaba muy por delante de la más renuente de las demás audiencias (la de Aragón, con 28 causas pendientes, en julio de 1787, como hemos visto). La singularidad gallega es reiteradamente esgrimida como explicación, tanto más plausible cuanto que tal diferenciación no se escuda en la propia afirmación o en el propio convencimiento, sino que resulta de una percepción o mirada exterior, la de los representantes del Estado en el territorio.

Cierto, también se encuentran datos, en las Relaciones, que singularizan a otros territorios, como ocurre, por ejemplo, con Cataluña, a cuya Real Audiencia se le reprocha, en 1788 , la «considerable omisión» advertida en una causa pendiente, a la sazón la principiada el 30 de abril de 1783 contra el Dr. Ignacio Vila y el llamado Benito Antonio Conchs, a quienes se acusaba de «haber proferido palabras injuriosas contra el gobierno», y tras cuyos nombres figura, anotada entre paréntesis, la mención «catalanes». Pero, por lo demás, no advierten las autoridades en las Relaciones, cosa alguna que singularice a Cataluña, lo que le permite a Campomanes escribir, en carta dirigida a Floridablanca el 27 de junio de 1788, que el Principado «cumple con toda exactitud». Años más tarde, en la «oración» pronunciada, ante las tres Salas, el 2 de enero de 1800, por el Regente de la Audiencia de Barcelona (Francisco de Arjona), y que acompañaba la publicación de los Planes o Estados que manifiesan el número de pleytos, causas y expedientes, tanto civiles como criminales, despachados en el año de 1799 por dicha Audiencia (Barcelona, 1800), se concretaba la noción de «horrendo» o de «atroz», que, por lo que se ve, no era infrecuente en la prosa con que los magistrados hablaban de los delitos que juzgaban. Para Francisco de Arjona eran crímenes «atroces» los homicidios, los robos cualificados, los adulterios, raptos y sacrilegios, así como otros «de igual naturaleza», sin que la imprecisión de esta última fórmula haga olvidar la precisión de los delitos anteriormente calificados como horrendos por el magistrado.

No ocurría lo mismo en Galicia, en donde el mismo Floridablanca advertía «el mayor número de delitos, horrendos y desconocidos muchos en el resto de la España», lo que achacaba al «gran número de habitantes de ese Reino y la falta de educación que tienen algunos de sus naturales», aunque ello no le impedía amonestar a los

11. El 26 de marzo de 1787 Floridablanca escribía a Campomanes urgiéndole «el más pronto despacho de los procesos criminales» y participándole el disgusto (sic) con que el Rey había visto lo muy atrasados que se encontraban en la Audiencia de Galicia. Una información detallada sobre los delitos, las penas y los delincuentes encausados por la Real Audiencia, ha sido recientemente suministrada por J. M. Palop Ramo, «Notas sobre la criminalidad en Galicia a finales del siglo XIII», in Conflictos y represiones en el Antiguo Régimen, Universidad de Valencia, Valencia, 2000, p. 181-208. 
magistrados de la Audiencia de la Coruña, imputándoles cierta responsabilidad en la situación ${ }^{12}$. Éstos reaccionaron sin tardanza, y en sendos correos el Regente y los miembros de la Sala del Crimen explicaron el caso a Floridablanca ${ }^{13}$, insistiendo en «la constitución, población y gobierno de este Reino, que, a la verdad, es distinto todo de lo restante de España». Poco sospechosa de «galleguismo» resultaba, desde luego, esta apreciación en boca del Regente de la Audiencia de Galicia, Don Felipe Díaz de Quijada Ovejero, prototipo del letrado formado por y para el Estado (colegial en Alcalá, Alcalde del Crimen y Oidor en la Chancillería de Valladolid, de 1762 a 1781, antes de pasar destinado a La Coruña).

Ahora bien, ¿cómo se explica que los delitos cometidos en Galicia recibiesen el tremendo calificativo singularizador de «horrendos»? Creo que ello se explica no tanto porque en Galicia encontremos también mayores porcentajes de violencia $(36,30 \%)$ que de latrocinio $(25,59 \%)$-cosa que ya sabemos que sucedía, igualmente, en Valladolid (norte) y en Sevilla (sur)-, cuanto porque aquí la correspondencia entre homicidios y robos es muy distinta: en el mes de junio de 1787, la Relación de la Audiencia de La Coruña registra prácticamente la misma criminalidad por muertes (41 causas) que por robos (43 causas). Por otra parte, el que los delitos gallegos fuesen también conceptuados como «desconocidos» en el resto de España confirma la singularidad del caso, aunque quizás haya que matizarla pensando en que un delito «desconocido» es también un delito del que la justicia no conoce, un asunto que escapa a la mirada vigilante del Estado. La ineficacia represora del aparato judicial en ciertos supuestos buscaría compensaciones haciéndose más presente en otros. Una coincidencia me parece aquí reveladora: lo mismo que en Andalucía, pero en porcentajes aún mayores, la justicia invade, en Galicia, el ámbito de la vida privada de los ciudadanos. El 22,02\% de las causas abiertas en la Audiencia de La Coruña reprimen delitos de carácter sexual y, concretamente, de amancebamiento. La justicia parece, pues, compensar con esta presencia represora su ausencia en otros ámbitos delictivos. Tal abundancia y la facilidad de represión de estos comportamientos pueden indicar, finalmente, tanto su banalidad y frecuencia como su relativa publicidad y control, en una sociedad como la gallega, dominada por el peso de lo rural, dispersa y cerrada al tiempo, y, al tiempo también, incontrolable y controlable según los supuestos.

12. Amonestación de Floridablanca al Regente de la Audiencia de Galicia Don Felipe Díaz de Quijada Ovejero (26 de abril de 1787). Algunos datos sobre la actividad judicial de la Audiencia de Galicia puede verse en O. Rey Castelao, Montes y política forestal en la Galicia del Antiguo Régiman, Universidad de Santiago de Compostela, Santiago de Compostela, 1995, p. 16-30. La conflictividad derivada del uso de montes y aguas fue constante e intensa en la Galicia del XVIII, V. J.M. Candal González, «Pleitos de aguas en la Audiencia coruñesa durante el siglo XVIIl», in Obradoiro de Historia Moderna, 2, 1993, p. 85-103.

13. El Regente de la Audiencia de La Coruña contestó a Floridablanca en dos correos fechados el 4 y el 16 de mayo de 1787 respectivamente. En el primero de ellos Díaz de Quijada comunicaba haber hecho presente las instrucciones de Madrid tanto a la Sala del Crimen como a las cabezas de partido. El segundo contenía un largo alegato sobre la situación, por lo que será ahora mi fuente principal. 
Dejemos, empero, la palabra al Regente de la Audiencia de La Coruña, quien, en su empeño por justificarse ante Floridablanca, desvela ciertos aspectos de la sociedad gallega con la mirada propia del viajero y la preocupación del magistrado. Hubiese o no leído a Montesquieu, lo cierto es que Don Felipe Díaz de Quijada asume una concepción de conjunto del cuerpo social, atendiendo a la implicación de sus diversos elementos: clima, geografía, economía, costumbres,... En este sentido, las observaciones del Regente tienen el doble interés de revelar no sólo la realidad gallega -que, en Madrid, se descubría aparentemente con sorpresa- sino también los esquemas intelectuales de un letrado arquetípico en funciones.

La relación con los elementos estructurales de Galicia era puesta de relieve, de forma explícita, por el magistrado cuando explicaba a Floridablanca «lo que es preciso suceda en este Reino por la disposición de su vecindario, su pobreza y extensión». Veamos, en su detalle, algunos de estos elementos.

1. La disposición del vecindario. No se trata aquí de una referencia a la distribución de la población sobre el territorio, sino de una apreciación sobre el carácter de los gallegos. ¿Cómo eran, pues, los gallegos vistos por un agente del poder judicial? El Regente de La Coruña se refiere a «la cavilación, rencor y deseo de venganza a que son inclinados estos naturales» para explicar la razón de que en Galicia se acumule más trabajo que en cualquier otro tribunal del Reino. La litigiosidad a que son dados los gallegos ocupa a los jueces con numerosas «desavenencias de poca entidad... porque en este país, por pequeña que sea la cuestión de injurias, reales o verbales, nunca cesa hasta llegar a la Sala del Crimen». Advirtamos la relevancia de la distinción entre las injurias «verbales» y las «reales», que además de confirmar la importancia de la afrenta pública -las palabras-, conformemente a lo que ocurría en toda la mitad norte peninsular, recoge también una segunda categoría, pues, si hemos de convenir en que la distinción no jerarquiza unas injurias tenidas por pertinentes desde el punto de vista judicial (las «reales») ante otras tenidas por irrelevantes o nimias (las «verbales»), lo que se deduce es la vigencia en Galicia de todo un aparato simbólico, de toda una serie de actos o actitudes, que, sin necesidad de recurrir a las palabras, servían para exteriorizar la afrenta y eran percibidos de esta guisa en el seno de unas comunidades cerradas en las que la necesidad de la respuesta -venganza o litigio- parece formar parte de una implícita codificación social.

Los magistrados de la Sala del Crimen de La Coruña no desentonaban del Regente cuando subrayaban, a su vez, «la cavilación e increíble espíritu de litigar de estos naturales», naturales que son, además, «inclinados a mentir», es decir a sustraer, con toda probabilidad, los fundamentos de aquella codificación ancestral a la mirada inquisitiva de los servidores del Estado. Retrato tan poco halagüeño se matiza, sin embargo, con una apreciación positiva, ya que «por otra parte, los gallegos no son tan holgazanes como lo restante de España».

Claro que, dando por sentado este presupuesto surgido obviamente de la observación, cabe preguntarse si ello era el resultado de un verdadero amor al trabajo y a la consiguiente prosperidad de la nación, como querían los ilustrados, o la simple conse- 
cuencia de un penoso hábito impuesto por las condiciones de vida. Las observaciones del Regente no dejan lugar a dudas, pues, en realidad, si los gallegos no son holgazanes es «porque a los hijos e hijas, aunque sean pequeños, los hacen trabajar más que lo que pueden sus fuerzas». El ideal del amor al trabajo resulta así transformado en una verdadera lacra de la sociedad gallega, el trabajo de los niños, que resulta de la pobreza y que propicia la mala educación ( «es muy cierto que en este Reino hay mucha pobreza y mala educación», observa el Regente), es decir la falta de escolarización de los niños, resultado todo ello, como no podía ser menos, de la propia «Constitución del reino».

2. La Constitución del Reino. «La población de este Reino no es como la de Castilla», afirma sentenciosamente el Regente de La Coruña. «Aquí, a excepción de las siete ciudades que están congregadas y algunas otras villas, todo lo demás está disperso y separado, y su gobierno se entiende por jurisdicciones y parroquias». El primer dato a tener en cuenta, pues, es la configuración física e institucional del territorio, «el cual, siendo el más dilatado y numeroso de la España, apenas tiene cincuenta pueblos formados, y todo el resto de su grande población consiste en unas débiles y miserables casas separadas y esparcidas en todo él, sin ninguna seguridad ni defensa, y expuestas a cualquier insulto». Territorio extenso, con población abundante pero dispersa en multitud de núcleos poco propicios a la concentración: se entiende que esta «disposición» complicara la misión, justiciera, cierto, pero al tiempo centralizadora y uniformizadora, de tan celosos magistrados.

Un instrumento fundamental al servicio de aquella misión era la escuela. Pero, en Galicia, « como las feligresías son tan grandes y viven en cada lugar tres o cuatro vecinos, y en el que más ocho o nueve, y éstos distan unos de otros mucho, no se puede disponer que para todos haya escuela, porque los niños no pueden vivir con el afán de ir y volver a sus casas desde la escuela todos los días, aunque se pusiese junto a la misma parroquia». Esta observación del Regente ofrece varios elementos de sumo interés. En primer lugar, la asunción por aquellos letrados ilustrados, y más alla de su esfera especializada de actuación, de ciertos ideales propiciados por las Luces: en el caso presente, el derecho universal a la educación («que para todos haya escuela»), si no la escolarización obligatoria. Además, cabe resaltar la implícita disociación -planteada, quizás inconscientemente, también como un ideal- de la escuela y la iglesia. La parroquia como referencia administrativa y religiosa, susceptible de generar un apéndice escolar, es una solución revisable, tanto más cuanto que no es una verdadera solución. La solución no es, sin embargo, fácil de arbitrar, pues choca fatalmente con el condicionamiento del habitat gallego. La correlación existente entre el nivel de escolarización y el grado de dispersión del habitat, cuya importancia ha sido puesta de manifiesto por recientes investigaciones ${ }^{14}$, era ya percibida, por un servidor perspicaz de la administración ilustrada, como el primer dato a tener en cuenta. Antes, propiamente, que la correlación con la riqueza.

14. Cf. J.E. Gelabert, «Niveaux d'alphabétisation en Galice (1635-1900)», in De l'alphabétisation aux circuits du livre en Espagne. XVI-XIXe siècles, Toulouse, 1987, p. 64-65. 
Este segundo dato era también recogido por el Regente, para quien no sólo los condicionamientos geográfico-administrativos dificultaban la escolarización de los niños gallegos. Ahora bien, ¿era la insuficiencia del excedente generado por la agricultura en Galicia lo que, al imposibilitar la apertura de una escuela o la retribución de un maestro, se oponía al progreso de la escolarización en las zonas rurales? ¿Cabe interpretar de esta manera la correlación entre instrucción y riqueza? Sin negar la importancia de este parámetro al final del proceso, conviene subrayar la relevancia de lo que ocurría al principio, a saber, la propia indisponibilidad de los niños para el trabajo escolar, en razón de su temprana utilización en la economía rural gallega. La economía familiar y su funcionamiento son un obstáculo inicial, por el recurso masivo al trabajo de los niños, pues, aunque pudieran éstos ir a la escuela (suponiendo así resuelto el principal condicionamiento), «los padres (que son pobrísimos) quieren más emplearlos, cuando llegan a siete u ocho años, a que vayan a llevar a pasto los bueyes de la labranza, que no a que se diviertan en la escuela». Surge aquí la duda de si la referencia a los «siete u ocho años» ha de ser entendida como una práctica en el comienzo de la instrucción o como una interrupción casi sistemática de la misma (cuestión obviamente importante para ponderar los niveles de alfabetización), aunque no menos importante sea advertir la insidiosa persistencia del dato geográfico: los niños son utilizados para «llevar a pasto» a los bueyes, trabajo en sí mismo poco penoso, a no ser por las distancias y tiempo consumidos en la operación. Finalmente, obsérvese como frente a la rentabilización inmediata de la fuerza de trabajo de los niños, el trabajo escolar es presentado como una simple «diversión», término que aunque sea empleado por nuestro magistrado no creo que le sea directamente imputable. Al utilizar este vocablo Don Felipe Díaz de Quijada no lo hace ciertamente suyo, sino que, consciente o inconscientemente, refleja, con toda fidelidad, las categorías mentales, la jerarquía de preferencias o prioridades, propias de una economía, doméstica y comunitaria, que, en amplias zonas, no conseguía sobrepasar los límites de la subsistencia. Ahora bien, ¿cambiaba la situación en las zonas más prósperas?

3. El ejemplo de San Salvador de Bergondo. El territorio denominado de Bergondo se extendía, no muy lejos de la capital coruñesa, entre Sada y Betanzos, al sur de la ría de Sada, origen del país de las Marinas. Las Marinas de Sada eran también conocidas como Marinas dos Condes por los muchos nobles que en ellas vivieron. A principios del siglo XVIII fue Sada lugar importante por sus fábricas de paños, lona, mantelería y lienzos, creadas por Adrián de Roo. Al desaparecer la manufactura de paños, pasaron las de jarcia y lona a El Ferrol, y las de mantelería y lienzos a La Coruña, aunque luego el gobierno creó allí la manufactura de cordelería para la Marina, para la que trajo abundante mano de obra extranjera. Esta actividad, sin embargo, cesó hacia 1770. Desde el punto de vista agrícola, la tierra era feraz y en ella se producían cereales, legumbres, frutas y vino, además de criarse ganado vacuno. Entre las parroquias de la demarcación, se encontraba la de San Salvador de Bergondo, próspera si hemos de creer al Regente de la Audiencia de La Coruña, quien la tenía por «la más rica y mejor cultivada que se hallará en el Reino de Galicia». Moraban en ella 
unas «mil seiscientas personas de confesión y comunión», lo que, en el contexto rural gallego era ciertamente notable, y aún más si tenemos en cuenta la estabilidad de la situación: el censo de 1920 asignaba a San Salvador de Bergondo 1.546 habitantes de hecho. Menos notable sería, probablemente, la «infinidad de niños de los dos sexos» que por allí pululaban, según observaba el Regente, no sólo por la evidente precariedad de los medios anticonceptivos de la época, sino más bien porque la economía familiar -y seguramente también la asalariada-, al utilizar la fuerza de trabajo de los chiquillos como cosa natural, incitaba en algún modo a la procreación.

Pues bien, un hermano del Regente de la Audiencia de La Coruña, prior a la sazón en el Monasterio de San Martín en Santiago de Compostela ${ }^{15}$, al ver a toda aquella chiquillería sin escuela, decidió financiar la enseñanza de primeras letras en San Salvador de Bergondo. Buscó, en primer lugar, a un maestro, y luego hizo que se previniese a los padres de las criaturas para que enviasen a sus hijos a la escuela, quedando entendido que el prior se encargaría no sólo de costearles la enseñanza, sino además de proporcionarles, a mediodía, «la comida regular que se acostumbra en este país», probablemente con la intención de prevenir la reacción negativa de unos padres quizás reacios a alimentar a quienes no se ganasen el sustento con sus brazos.

Del alcance que podía tener en Galicia la noción de riqueza aplicada a una feligresía como la de San Salvador de Bergondo da idea, por otra parte, el hecho de que el buen prior no se contentase con costear la enseñanza y el alimento matutino, pagando también de su bolsillo el vestido de aquellos niños, pues «cuando les veía sin camisa les mandaba hacer camisas y calzoncillos, que es el vestido regular de aquí», según anota el Regente. De estas sucintas prendas no parece que dispusiese la mayoría de los niños, ya que su benefactor «tenía de continuo dos costureras trabajando» para paliar tan triste situación. Hubiese o no exageración en el dato aportado por el Regente, lo cierto es que el resultado no fue el apetecido: «aunque al principio asistieron algunos a la escuela -observa el magistrado- , ya no van, porque los padres dicen que más utilidad les tiene que vayan a guardar los bueyes», a pesar de que el prior de San Martín, para no hacer gravosa a las familias la existencia de los niños no rentables, continuaba distribuyéndoles la comida «regular» a mediodía y haciéndoles sus camisitas ( $\mathrm{sic}$ ). Adviértase, de paso, la ambivalencia del término «utilidad»empleado por el Regente, que, como es sabido, encarna una de las nociones más definitorias de la Ilustración: a la «utilidad» entendida como orientación del proyecto colectivo se contrapone la «utilidad» de los campesinos gallegos, quienes, en 1787, la entendían de bien distinta manera.

15. El monasterio de San Martín Pinario, de imponente fábrica, era un convento benedictino, cuya historia va unida a los orígenes y desarrollo de la capital compostelana. De su abadía llegaron a depender más de treinta monasterios y prioratos, que, en el siglo XVIII, le aseguraban sustanciosas rentas, de lo que da testimonio no sólo la actitud del prior sino también la construcción de la hermosa escalera (concebida hacia 1772) que adorna la portada de la iglesia. Adviértase, por otra parte, el ejemplo de vinculación familiar en los aparatos estatales y eclesiásticos que ilustra el caso de Don Felipe Díaz de Quijada Ovejero, Regente de la Audiencia, y de su hermano, segundo personaje del monasterio de San Martín. 
Con todo, el caso narrado por el Regente ilustra la presencia fundacional de la Iglesia en los circuitos de financiación del sistema escolar gallego. Lo pertinente aquí no parece ser, desde luego, la apariencia caritativa de la actividad del prior, sino el empeño puesto en la realización de un propósito, siendo los aspectos asistenciales (comida y vestido) fuertes medios incitativos para la consecución del objetivo. No es éste el alivio de la pobreza o el socorro de los indigentes, sino la escolarización de la población infantil de San Salvador de Bergondo.

La pobreza es otro de los grandes rasgos estructurantes de la sociedad contemplada por el Regente de La Coruña. En San Salvador de Bergondo -la feligresía «mejor poblada y cultivada» de la zona- el pan es la base de la dieta alimenticia, régimen por cierto habitual en las capas populares y en otros territorios de la península. Lo que es ya menos habitual es la escasez de recursos disponibles para asegurarse el pan de cada día. Así, no se encuentran en San Salvador «seis hombres que tengan pan para todo el año; doce que, después de éstos, lo tengan para la mitad; y a todos los demás no los alcanza el trabajo si no es para dos o tres meses de pan». La afirmación quizás fuese exagerada -al Regente le interesa cargar las tintas para reforzar la argumentación que expone a Floridablanca-, pero la realidad reflejada por esa representación matemática era la escalofriante falta de recursos susceptibles de garantizar niveles mínimos de subsistencia. El «alcance» del trabajo no implica tanto aquí escasez del mismo cuanto insuficiencia de su producto. Así se explica que, para alimentarse el resto del año, los campesinos de la zona tengan que dirigirse al prior de Bergondo, ahora encargado de materializar la actividad asistencial de la Iglesia. El prior suministra a los campesinos de su jurisdicción lo que constituye el resto de su régimen alimenticio: unos ferrados de maíz ${ }^{16}$, que convierten en harina para echarla en un pote o puchero, en el que cuecen unas berzas con un poco de «unto» o manteca, comiéndoselo, advierte el Regente, «sin más pan». Éste era el sustento ordinario del campesinado de San Salvador de Bergondo.

Nada de extraño tiene, en tal contexto, que la autosuficiencia alimenticia situara socialmente por encima del campesino ordinario asistido por su señor eclesiástico. Por eso, «se tiene casi por caballero aquél que tiene pan y puerco para todo el año», de modo que cuando se habla, en Galicia, de un labrador rico, «la última ponderación es decir: es labrador de pan y puerco», lo que equivalía a ver, en la representación colectiva, a un personaje feliz, puesto que podía mantenerse todo el año con pan de maíz y tocino. El labrador de pan y puerco, pues, como contrapunto gallego del castellano caballero de capa y espada, nos hace ver, de forma fehaciente, cuán general era la indigencia, y cómo la mera autosuficiencia alimenticia proporcionaba un relieve social, cuya manifestación, en el lenguaje popular, constituye una peculiar representación de un ideal que bien pudiera hacer suyo Sancho Panza.

De la pobreza general resulta así un régimen alimenticio paupérrimo, y esa misma pobreza, unida al trabajo que a los niños se impone en las familias, explican la

16. Era el ferrado una medida de capacidad, usada en Galicia, para granos, legumbres y otros frutos secos, cuya equivalencia podía oscilar, según lugares, entre trece y dieciséis litros. 
falta de escuelas o, en cualquier caso, la ausencia en ellas de sus destinatarios, con el resultado inevitable: la «mala educación» que el Regente de La Coruña reprocha a los gallegos. Pero de ella hay que distinguir, cuidadosamente, la «mala crianza» que, en opinión del Regente, es también «inevitable entre todas las personas del Estado General de Galicia». Tal fatalidad atribuida al estado llano tiene asimismo explicación, en funcion de las condiciones materiales de vida y de vivienda propias del habitat rural gallego. Las viviendas gallegas, por la promiscuidad que engendran y la ausencia de espacios privados, chocan de frente con el ideal ilustrado de la buena crianza de los jóvenes. «Todos estos labradores -advierte el Regente- para su habitación no tienen más que unas casas terrenas, y las más sin separación alguna, de modo que adonde duermen los padres duermen los hijos e hijas, y duermen también los bueyes y caballerías». Los peligros que resultaban de esta situación -no exclusiva, desde luego, del campo gallego, pero, sin duda, más generalizada que en otras zonas del agro español-eran, perspicaz y deliciosamente, denunciados por el Regente: «de suerte que se ven todas las operaciones que hacen unos y otros, y se oyen todas las conversaciones que tratan, en lo que se origina mucho escándalo para los jóvenes». Probablemente esta promiscuidad vivida en espacios cerrados, aislados o mal comunicados, propiciaba la relajación de costumbres en la sociedad gallega de que da testimonio el elevado porcentaje de causas por amancebamiento seguidas en la Audiencia de Galicia ${ }^{17}$, porcentaje sobre el que no parece aventurado pensar que, a pesar del plausible celo compensatorio desplegado por la Justicia en esta materia ( por iniciativa propia o como receptáculo de la litigiosidad gallega?), quedaba muy por debajo de la realidad.

No es tampoco inverosímil que a esta libertad de costumbres contribuyese igualmente la condición viajera de muchos gallegos, pues peor condición que la de aquellos a quienes no «alcanzaba» el trabajo más que «para dos o tres meses de pan» era la de quienes, carentes de cualquier trabajo, se veían obligados a la emigración temporal para subsistir. Fenómeno éste tan enraizado que el Regente de La Coruña no olvida de señalar a Floridablanca, entre los rasgos estructurantes del territorio, «la ausencia que, regularmente, acostumbran hacer estos naturales a cierto tiempo». Ello obstaculizaba la acción de la Justicia, cuando de reunir testigos se trataba, por ejemplo, ya que era preciso «librar requisitorias a países distantes para su ratificación o esperar a que se restituyan a sus casas». Aventuremos también otra consecuencia de la emigración: ausencias de unos, saudades y soledades de otros u otras bien pudieren explicar la frecuencia de los amancebamientos. Esta consecuencia, plausible desde el punto de vista de los comportamientos y pulsiones individuales, lo es tanto más cuanto que la Justicia era, con frecuencia, una Justicia ausente en las zonas rurales, de caseríos aislados o desarticulados. «De cierto número de estas casas -anota el Regentese forma una Jurisdicción, que a veces tiene cinco y seis leguas de extensión, gobernada por sólo un juez lego y un escribano de número, o ignorantes o de mala fe, los que regularmente viven a larga distancia uno de otro, sin que, en las más de ellas, ha-

17. El 22,02\% en 1787 (supra), Io que supone, en la relación de la Audiencia, la tercera partida de delitos perseguidos, tras los robos y las muertes. 
ya abogado, ni médico, y más que un mal sangrador». Ausencia de los naturales, ausencia de profesionales, ausencia del Estado: la Galicia de 1787 es realmente un país ausente del engranaje español.

Concluido el inventario de los problemas, quedan por ver las soluciones que los magistrados de la Audiencia de Galicia, al unísono con su Regente en la denuncia, sugieren al gobierno ${ }^{18}$. La visión de los jueces de la Sala del Crimen gallega coincide con la del Regente en su mayor parte, incluso literalmente, pero ofrece la novedad de incluir algunas propuestas tendentes a mejorar la situación. En realidad, el contenido de dichas propuestas, más que proyectos estructurados, revela implícitamente otras tantas carencias o defectos, que el Regente, quizás por la prudencia a que le incitaba su función, había preferido pasar por alto. Estas carencias se refieren fundamentalmente a la presencia del Estado, tanto en sus manifestaciones represoras como en aquellas otras que pudiéramos considerar de carácter más administrativo o asistencial.

1. Ausencia del Estado represor. La primera limitación que encuentran, en el ejercicio de sus funciones, los aparatos de control y represión es la distancia: distancia entre el lugar en que la Justicia impone su presencia y el lugar de comisión de los delitos («que generalmente se cometen en despoblado»); distancia que ponen los delincuentes entre ellos mismos y la Justicia persecutora, siendo, a estos efectos, el vecino Reino de Portugal la puerta natural por la que salen, huidos, aquéllos; distancia que opera, finalmente, no sólo en sentido espacial sino también temporal (la comisión de los delitos no llega a noticia de los jueces «hasta pasado algún tiempo después de haber sucedido»).

Es esta combinación de efectos espaciales y temporales de la distancia gallega la que hace que las articulaciones del aparato de justicia resulten inoperantes ${ }^{19}$. A la «constitución» de Galicia se añade el carácter de los gallegos («la cavilación e increíble espíritu de litigar») para explicar la formación de farragosos procesos, de suerte que «una causa criminal que en cualquiera otra parte, podría concluirse en dos meses, necesita aquí un año».

La diferencia gallega, sin embargo, no resulta sólo de circunstancias exteriores a los propios aparatos de control. «La mala práctica de los escribanos» resulta también incriminada, «la naturaleza y circunstancias de los jueces» son asimismo motivo de queja para los magistrados de la Audiencia, que contemplan con mirada severa a las justicias inferiores, representantes locales del orden- «muchos de ellos tan ignorantes

18. Paralelamente al Regente de la Audiencia, el gobernador y los magistrados de la Sala del Crimen (D. Francisco Javier de Contreras, D. José Heredia, D. Manuel Romero y D. Miguel Alfonso Villagómez) exponen, en un escrito dirigido a Floridablanca el 16 de mayo de 1787 por la vía reservada, su propia visión del caso.

19. Los magistrados de la Sala del Crimen insisten, de forma reiterada, en «la distancia que regularmente hay desde las casas de los testigos a la del juez», en los largos recorridos que imponen «las frecuentes salidas de éste y su escribano fuera de su jurisdicción, por varios incidentes que suelen ocurrir en las mismas causas», en «la larga distancia a que también se hallan comúnmente el Asesor, Promotor Fiscal, y demás Abogados que defienden a los reos», $o$ en «el tiempo que unos y otros necesitan para tomar los autos y despacharlos». 
que ni aun saben leer ni escribir»-, culpables, por omisión o impotencia, de los desmanes de los subalternos ${ }^{20}$.

Ahora bien, hay una razón más profunda que explica tal situación y que, en realidad, hace que ni los jueces inferiores sean enteramente responsables de su ignorancia, ni la constitución de Galicia o el carácter de los gallegos constituyan los únicos elementos de la argumentación, a pesar de su reiterada importancia. A estos motivos, extensamente expuestos, pueden añadirse otros, que los magistrados de La Coruña no dejan de recoger en forma breve, pero inequívoca, considerándolos como todavía «más poderosos» $(s i c)$. Son los que llevan a que el Estado permanezca ausente de la escena, en esos escenarios en que se manifiesta el primer nivel del control social y, en su caso, de la represión consiguiente, que son, precisamente, los más cotidianos, los que la percepción popular mejor distingue. Y si el Estado está aquí ausente es porque la Iglesia ha ocupado el terreno, reservándose la jurisdicción. Resulta, así, «hallarse en este Reino la mayor parte o casi toda la jurisdicción ordinaria enajenada y depositada en los Obispos, Cabildos, Monasterios, que son los que nombran los jueces», circunstancia cuyas repercusiones van más allá de la simple instrumentación inicial del ius puniendi, en la medida en que afecta a un aspecto fundamental de la represión de los comportamientos durante el Antiguo Régimen, cual es la economía de la Justicia.

Dos modelos se oponen aquí: el arcaizante, representado por la Iglesia, la cual, ya fuese por tacañería o por fidelidad a una concepción pura (bíblica) de la administración de justicia, no retribuía a los jueces que nombraba, y el moderno, que es lógicamente el que propugnan los magistrados de la Audiencia, para quienes la retribución de la función es aspecto inseparable de la deseable profesionalización. Las justicias de nombramiento eclesiástico no perciben más dotación que «el producto del Juzgado», esto es la resultante de su participación lucrativa en las penas pecuniarias impuestas por ellas mismas. Ahora bien, este «producto» era insignificante en las causas criminales seguidas en Galicia, en razón de dos parámetros que ya nos son familiares: la «constitución» del Reino, por una parte, en su variante «pobreza de los reos», y la «cavilación» de los naturales, que, en este caso, se manifiesta en la añaga-

20. Así se explica, según los magistrados de la Audiencia, «que los escribanos de número sean los que forman los procesos, los que o procuran con habilidad encubrir los delitos, o, como carecen muchas veces del auxilio de abogados y buenos cirujanos, los sustancian con tales nulidades y defectos que, cuando vienen las consultas a la Sala, es preciso enmendarlos, o dando comisión a un Receptor del Tribunal para que evacúe la causa según las reglas que se le prescriben, o instruyendo a las mismas justicias de lo que deban practicar; y sucede frecuentemente que estas advertencias llegan tarde, y cuando ya es imposible hacer los reconocimientos de los peritos y practicar las demás diligencias necesarias a fin de acreditar la primera y principal parte de un proceso criminal, que es el cuerpo del delito». (El subrayado es mío). Repárese, una vez más, en la incidencia del factor tiempo, tributario del espacio gallego, en la desarticulación del funcionamiento de los aparatos de control y justicia, aunque, junto a este aspecto, no haya que olvidar el otro gran problema consistente en «la omisión de las justicias ordinarias, dimanada de hacerse el nombramiento de muchas de éstas por los dueños jurisdiccionales en personas ineptas, y de ser excesivo el número de escribanos, que confundían las causas» (carta de Campomanes a Floridablanca, fechada el 19 de abril de 1788). Era, pues, un problema o argumento al que las autoridades de Madrid se mostraban ciertamente sensibles. 
za de quienes, posesores de algunos modestos bienes apetecidos por las justicias, «halian suma facilidad en justificar que son de sus mujeres o de sus hijos y hermanos». No cabe duda de que la promiscuidad y confusión de seres y enseres dentro del habitat gallego propiciaba la «facilidad» así denunciada y la correspondiente escapatoria legal. Con no poca hipocresía y suma habilidad los magistrados de La Coruña certifican el hecho de que los jueces ordinarios «después de haber trabajado mucho y haber padecido varias incomodidades, no tienen ningun premio», deplorando que la Sala no tenga «medios y arbitrios para recompensar sus fatigas, sus derechos y su celo». Con otros servidores de la justicia tenían, en cambio, más miramientos los magistrados de la Audiencia gallega, bien es verdad que se trataba de auténticos profesionales, como los abogados y procuradores. Triste destino era el de éstos en Galicia, actuantes cuasi benévolos en unas causas, la mayor parte de las cuales eran de pobres de solemnidad. Solidaria con estos profesionales, la Sala viene en su auxilio aludiendo a la necesidad de tener con ellos «alguna condescendencia», para que de este modo «puedan también dedicarse y desempeñar los negocios de utilidad, con lo que sostienen sus casas y familias». Aventurado sería, claro está, fijar los límites de tal condescendencia: ¿mera benevolencia hacia esos otros letrados, durante las tres horas diarias de audiencia practicadas en La Coruña, o complicidad interesada en el avance o resolución de las causas de utilidad? Y ¿utilidad para quién? In dubio pro reo: hecha cuenta del lugar en que figura esta confesión -un informe de la propia Sala del Crimen a Floridablanca-apostemos que más había de la primera que de la segunda.

Conviene atenuar la impresión negativa dejada por la sorprendente confesión de los magistrados, haciendo justicia a su conciencia profesional, tal como ésta podía manifestarse en otros supuestos más significativos, y, en concreto, a la hora de imponer el castigo. La respuesta de los jueces a las recriminaciones de Floridablanca, revela el fundamento de las apreciaciones negativas del Conde. Ni por una «mínima indulgencia», ni por otros «vicios feos y abominables» están las causas criminales de la Audiencia de La Coruña más atrasadas que en cualquier otro Tribunal del Reino; al contrario, los magistrados que componen su Sala del Crimen bien quisieran poder «imponer a los delincuentes las penas determinadas por las leyes y correspondientes a sus delitos», pero no pueden, porque un tribunal de justicia digno de tal nombre no puede «suplir la falta de pruebas», ni conciliar «la delicadeza y escrupulosidad» de las leyes con «la confusión y defectos» de los procesos. Así se explica que «muchas veces aquellos delitos que, por el rótulo y apariencia, parecen los más horrendos, se castigan con penas extraordinarias y que a primera vista no corresponden a la idea que se forma de ellos». De donde se deduce:

1. que lo que, propiamente, horrorizaba a Floridablanca no era tanto el supuesto horror de los delitos cometidos en Galicia cuanto su impunidad o su insuficiente castigo;

2. que la noción de «horrendo» podía tener una connotación muy distinta según se viera desde Madrid (calificación administrativa dimanante de una apreciación inspirada por una determinada política criminal) o desde Galicia (apariencia de la realidad);

3. que el recurso a las penas extraordinarias reivindicado por los magistrados de La Coruña no parece que deba ser interpretado como un aferramiento a algo (casi) ar- 
caico en el más arcaico de los territorios de la Corona, sino como el medio utilizado por unos juzgadores escrupulosos y respetuosos del procedimiento para corregir las insuficiencias de la práctica ${ }^{21}$. No otra explicación tiene el que unos letrados, que contemplan con mirada ilustrada la situación del territorio que administran judicialmente, recurran, con la frecuencia que ellos mismos reconocen, a una institución que suscitó acerbas críticas por parte de los letrados ilustrados. Adviértase, con todo, la ambigüedad de la propuesta, tanto más relevante cuanto que las categorías mentales de los cuatro componentes de la Sala del Crimen de La Coruña reflejan perfectamente la jerarquía ilustrada, pues arreglan sus determinaciones «a las leyes del Reino, a su conciencia, y a su honor», ordenación trivial pero significativa.

2. Ausencia del Estado asistencial. El aspecto preventivo de una adecuada política criminal era otro de los caballos de batalla de los letrados reformadores. Un Estado que recoge, encauza o fomenta es un Estado que castiga menos, y, ya fuese por razones filantrópicas o políticas -el gobierno podía desear que se acelerase la ventilación de las causas para hacer más evidente la eficacia de sus aparatos de Justicia, y la judicatura para trabajar menos o mejor-, lo cierto es que se percibe claramente, al menos como aspiración, una tendencia al alivio de la administración de justicia en aras de una mayor corrección previa a un hipotético o ulterior castigo. El verdadero carácter de esta tendencia correctora (¿preventiva o utilitaria?), así como la delimitación de sus destinatarios y las razones de la misma, son cuestiones que quedarán aquí sólo apuntadas, pues mi intención es referirme ahora a las propuestas de instrumentación de esa corrección supuestamente preventiva, tal como eran vistas desde Galicia.

La primera solución contemplada por los magistrados de La Coruña es el hospicio. En él ve el Regente de la Audiencia la respuesta a la «mala crianza» de los gallegos, pues si la «constitución» del Reino y la «falta de educación» de sus naturales eran los dos grandes obstáculos con que tropezaba la acción del Estado en Galicia, obvio resulta que más fácil era enfrentarse con el segundo que con el primero. Ahora bien, apenas apuntada la solución despuntan las dificultades prácticas de su concreción. En primer lugar, la dimensión misma de las necesidades, excesiva para aquellos administradores bien intencionados («por muchos hospicios que se fabricasen, no

21. Al justificar las razones por las que no se puede administrar justicia en Galicia con la brevedad conveniente, como en el resto de España (sic), y al cuestionar la práctica habitualmente seguida, el Regente denuncia el uso que del arbitrio judicial hacían los jueces ordinarios: «no hay que admirar que en las relaciones mensuales ponga, por ejemplo, la Sala del Crimen un hecho de un parricidio, porque así les vino la noticia, y en la ejecución de la sentencia se le absuelva al reo, porque los testigos, el escribano y el juez, todos, contribuyeron al fin de desfigurar el hecho, y estos jueces no tienen arbitrio si no es para absolver». El elitismo de aquellos letrados les lleva, pues, a reivindicar para sí, si no por principio sí por conciencia profesional, lo que execran en los jueces no letrados, en razón de un a priori general de inspiración ilustrada, pero, por lo que se ve, de alcance más teórico que práctico. Por otra parte, el que, a título de ejemplo, al Regente no le venga a las mientes otro delito que un parricidio me parece, en algún modo, revelador de una situación de hecho, que explicaría también, aunque de modo parcial y secundario, el «horror» de Madrid ante los delitos que se cometían en Galicia y su relativa impunidad. 
eran capaz de bastar para la educación de la vigésima parte de la juventud pobre que hay en Galicia»); y, por otra parte, la obtención de los recursos inherentes a su financiación. La autofinanciación será siempre insuficiente («un joven, en muchos años, aunque trabaje, no puede costear el sustento con que se le ha de contribuir»), a la Iglesia no se quiere o no se puede recurrir («los eclesiásticos del reino hacen bastante en socorrer a los pobres labradores en todo el tiempo que se hallan sin pan, hasta que cogen su nueva cosecha»), y, como no parece merecer la pena que el Estado invierta en Galicia ( «al Rey no es regular cargar esta contribución»), la conclusión del Regente es de una claridad meridiana y de una ingenuidad asombrosa: «en Galicia los hospicios son dificultosos de mantener».

El tono varía ligeramente, para hacerse más acusatorio, en la exposición de los magistrados de la Sala del Crimen. Las carencias de la administración no encuentran ahora tan fácil disculpa. En Galicia faltan cárceles, y las que hay son tan precarias que constituyen una verdadera incitación a la fuga. Pero con ser esto grave, lo peor es que, una vez decretada la prisión preventiva por el juez ordinario, no hay subalternos ad hoc encargados de la custodia de los reos, sino que, mientras éstos esperan su traslado o juicio, son los propios vecinos del lugar de detención quienes han de asumir dicha tarea, lo que no sólo les acarrea molestias (la «distancia» entre sus casas y la prisión aparece, una vez más, como un dato relevante), sino incluso castigos impuestos por la Audiencia, que, por lo visto, no disponía de otro medio para incitar a los gallegos al civismo ${ }^{22}$.

La pobreza ${ }^{23}$, la promiscuidad, la emigración temporal, son otros tantos elementos de la «constitución» de Galicia que explican la formación de dos grupos, el de las prostitutas y el de los expósitos, más nutridos aquí, al parecer, que en otros territorios de la Corona ${ }^{24}$. «En ningún otro hay tanto número de mujeres prostitutas y escandalo-

22. Los magistrados de La Coruña señalan «la falta de cárceles, y la poca o ninguna seguridad de las que hay, de manera que para precaver la facilidad con que los reos pueden fugarse de ellas, tienen los vecinos la terrible molestia y vejación de custodiarlos día y noche, viniendo a una, dos o más leguas de distancia, abandonando sus casas y el cuidado y cultivo de sus bienes, y sufriendo muchas veces prisiones y las penas que esta Sala les impone, a proporción de la omisión y culpa que han tenido en la fuga de los reos, que sucede frecuentísimamente». En Madrid, la situación es juzgada severamente: «rara es la causa de gravedad donde los reos no están ausentes o se hayan escapado de la prisión, y no se toma providencias contra los justicias y encargados de la custodia de ellos, disponiendo a lo menos se trasladen a la capital, no siendo seguras las cárceles donde cometen los delitos». Adviértase el contraste entre la actitud de una administración central, preocupada ante todo por la eficacia, y la de unos magistrados, que, al denunciar la inoperancia del Estado, recogen con exactitud las realidades locales (al margen del interés exculpatorio que pudiesen tener en su presentación).

23. No cabe duda de que para los magistrados de la Audiencia gallega la pobreza del territorio es verdadera pobreza, en el sentido en que el discurso ilustrado (administrativo, legislativo, económico,...) trató de definirla (Vd. J. Soubeyroux, «Langage et idéologie: "pobre" et "pobreza" au dix-huitième siècle», in Les Langues Modernes, n. 4, 1979, p. 365-379). Significativo resulta, en este sentido, el que las autoridades madrileñas adviertan que las relaciones de Galicia nada dicen sobre la «recolección» de vagos.

24. Dejando aparte el grupo de los vagos, al que en otros lugares me refiero, tres grupos marginales retienen la atención de Campomanes en su correspondencia con Floridablanca: el de los mendigos -al que los magistrados de la Audiencia conceden menos atención, quizás por la confusión con los vagos que, a pe- 
sas», anotan los magistrados de la Sala del Crimen de La Coruña, adjuntando al tipo penal de la prostituta el de la mujer escandalosa, menos habitual (aunque no inédito) en las tipificaciones de los legistas ${ }^{25}$, lo que constituye un nuevo indicio de la libertad de costumbres imperante en Galicia, libertad que, en su variante femenina, choca a aquellos letrados, aunque más dificil es deducir de su discurso la verdadera causa del escándalo: ¿libertad asumida o forzada por las circunstancias o la necesidad? Algo de las dos explicaciones habría en el fondo de unos comportamientos no lo suficientemente explícitos para acarrear la calificación de prostitución o de amancebamiento, pero sí claramente transgresores, aunque sea muy difícil evaluar el peso específico de cada una de ellas.

Lo que la Audiencia deplora, con este motivo, es que no haya, en todo el «dilatado» reino de Galicia, una sola galera (cárcel de mujeres), hospicio o casa de corrección, contrariamente a lo que ocurre en otros lugares de España, en donde la necesidad es menos sensible. No cabe, pues, extrañarse de que las mujeres prostitutas y escandalosas gocen de una «absoluta impunidad en sus excesos», ni de que la carencia de dichos establecimientos imposibilite el combate contra otros muchos delitos. Dejando al margen lo que de exculpatorio pudiese haber en estas alegaciones, lo cierto es que la denuncia de las carencias del Estado, tanto desde el punto de vista represor como asistencial, no puede ser más clara.

En el caso del segundo grupo, el de los expósitos, la denuncia reviste el inéquivoco perfil utilitario ilustrado. Cierto, la primera alegación tiene un caracter filantrópico, ya que es un sentimiento «doloroso y sensible» ante «el infinito número de estas miserables criaturas» que hay en Galicia, lo que, obviamente, certifica la relajación de costumbres advertida y la movilidad sexual que la engendraba. De esta verificación pasamos a otra no menos evidente: la inexistencia de inclusas o de hospitales de expósitos en Galicia, en donde serían tan necesarios, con su correlativa consecuencia: el fallecimiento de la «mayor parte» de las criaturas abandonadas, cuyo seguimiento y paradero al Tribunal le resulta sumamente arduo conseguir. Pero la técnica del internamiento o «recogimiento», propugnada por los magistrados de La Coruña, que, en el caso de las mujeres, podía parecer como prioritariamente preventiva, ofrece, en el caso de los expósitos, un aspecto mucho más utilitario: al no implantar en Galicia estos establecimientos el Rey pierde «buenos soldados y muchos brazos útiles para la agricultura y las artes». La ausencia del Estado es aquí tanto más grave cuanto que resulta antieconómica.

sar de las proclamas legales, se daba en la práctica-, a los que había que «recoger»; el de «las mujeres», que había que castigar primero, aunque, luego, se buscase su enmienda; el de los niños, a cuya educación y mantenimiento debía acudirse (Campomanes transmite el sentir de los magistrados, elaborándolo de esta forma jerarquizada: los esfuerzos son vanos, en Galicia, «por no haber hospicio, casa de corrección ni misericordia, donde recoger los mendigos y castigar las mujeres abandonadas, [y] era preciso proveer de remedio para facilitar la enmienda de éstas, educación y mantenimiento de los niños»).

25. Sobre este extremo, aporta interesantes datos la tesis doctoral (inédita) de Christine Benavides, Les femmes délinquentes à Madrid au dix-huitième siècle, Université d'Aix-en-Provence, 1998. 
Revelador discurso, pues, el de estos letrados de la Audiencia de La Coruña, que concilia disimulados aspectos inmovilistas con otros en los que aparece claramente la preocupación por el país que administran y su articulación en el conjunto del Estado ${ }^{26}$. Por ello, una vez situado en el contexto de las causas pendientes, el discurso de los magistrados de La Coruña ofrece mayor número de elementos específicos que de elementos comunes a los demás territorios implicados en el asunto. El testimonio que aporta sobre la realidad gallega en el siglo XVIII es de primer orden. Pero, al tiempo, ayuda singularmente a comprender el papel y la función que aquellos letrados se asignaban. En este sentido, dicho discurso, tanto en su vertiente explicativa como en su aspecto exculpatorio, da también testimonio de las críticas y aspiraciones de una pieza fundamental del engranaje estatal.

26. En este sentido, la función de pivote en una red uniformizadora fue perfectamente asumida por los magistrados de La Coruña, a cuya información se debe la propuesta de Campomanes para que «se formase en el Consejo expediente para tomar providencia sobre arreglo de escribanos, fundación de hospicios, establecimiento de galera para mujeres y demás» (19-IV-1788). 